I. Ben-Zvi, T. Rao, A. Burrill, X. Chang, J. Grimes,

J. Rank, Z. Segalov, and J. Smedley

Brookhaven National Laboratory

Upton, NY 11973-5000

April, 2006

*This manuscript has been authored by Brookhaven Science Associates, LLC under Contract No. DE-AC02-98CH10886 with the U.S. Department of Energy. The United States Government retains, and the publisher, by accepting the article for publication, acknowledges, a world-wide license to publish or reproduce the published form of this manuscript, or allow others to do so, for the United States Government purposes. 


\section{DISCLAIMER}

This work was prepared as an account of work sponsored by an agency of the United States Government. Neither the United States Government nor any agency thereof, nor any of their employees, nor any of their contractors, subcontractors, or their employees, makes any warranty, express or implied, or assumes any legal liability or responsibility for the accuracy, completeness, or any third party's use or the results of such use of any information, apparatus, product, or process disclosed, or represents that its use would not infringe privately owned rights. Reference herein to any specific commercial product, process, or service by trade name, trademark, manufacturer, or otherwise, does not necessarily constitute or imply its endorsement, recommendation, or favoring by the United States Government or any agency thereof or its contractors or subcontractors. The views and opinions of authors expressed herein do not necessarily state or reflect those of the United States Government or any agency thereof. 


\title{
DIAMOND SECONDARY EMITTER
}

\author{
I. BEN-ZVI, T. RAO, A. BURRILL, X. CHANG, J. GRIMES, J. RANK, Z. SEGALOV, \\ AND J. SMEDLEY \\ Brookhaven National Laboratory, Upton, New York
}

\begin{abstract}
We present the design and experimental progress on the diamond secondary emitter as an electron source for high average power injectors. The design criteria for average currents up to $1 \mathrm{~A}$ and charge up to $20 \mathrm{nC}$ are established. Secondary Electron yield (SEY) exceeding 200 in transmission mode and 50 in emission mode have been measured. Preliminary results on the design and fabrication of the self contained capsule with primary electron source and secondary electron emitter will also be presented.
\end{abstract}

\section{Introduction}

In recent years, there has been considerable interest in developing high brightness photo injectors with high average current, even up to $1 \mathrm{~A}$, for variety of applications [1-3]. One of the key issues to be addressed for such injectors is the generation of the required high current reliably and reproducibly. The injector should be capable of delivering charge up to tens of $\mathrm{nC}$, with a bunch length of a few to tens of $p s$ at a repetition rate in the range of tens to hundreds of MHz. Furthermore, the transverse and longitudinal emittance of the electron beam should be very small. A typical approach has been to irradiate a suitable photocathode material with a laser in the presence of an electric field so that the emitted electrons can be quickly accelerated to relativistic velocities. The choices of the field, cathode, and laser are dictated by the application. The high field achievable in a superconducting RF (SRF) cavity makes it an attractive candidate for in $\mathrm{CW}$ operation. Metal photo cathodes have been used very successfully in low average current injectors. Although these cathodes have low quantum efficiency (QE) and require UV photons, they are rugged and inert and hence are the preferred cathode material in a number of injectors [4-6]. However, to deliver high average currents with the present state-of-the-art laser systems, the cathode should have higher $\mathrm{QE}$ than metals while preserving the ruggedness of the metal cathode. In addition, the cathode material should be relatively insensitive to the contaminants and should not contaminate its environment either, especially that of the SRF cavity. It should be capable of emitting high charge and current, have a fast response to laser pulse, a low 
thermal emittance, long life and be simple to install. Since the requirements on the laser energy and power are directly linked to the $\mathrm{QE}$ of the cathode, higher the $\mathrm{QE}$, more relaxed are the performance requirements on the laser.

Semiconductors such as alkali antimonide and Cs:GaAs have been investigated successfully and shown to yield a $\mathrm{QE}$ of $>10 \%$ at visible and near IR wavelengths $[7,8]$. However, these cathodes require an ultra high vacuum, and a complicated load-lock system for installing into the RF injector. In addition, Cs, an element typically present in these cathodes, may contaminate the cavity over time and degrades its performance. In this paper we present the possibility of isolating these cathodes from the accelerating structure and simultaneously enhancing the current/charge more than one hundred fold by using a diamond layer between the cathode and the accelerating structure. Although the concept has been developed for photo cathodes and RF injectors, it can be easily adapted to other primary electron sources and accelerating structures.

\section{Concept:}

The schematic of the Secondary Emission Enhanced Photoemitter (SEEP) is shown in Figure.1.

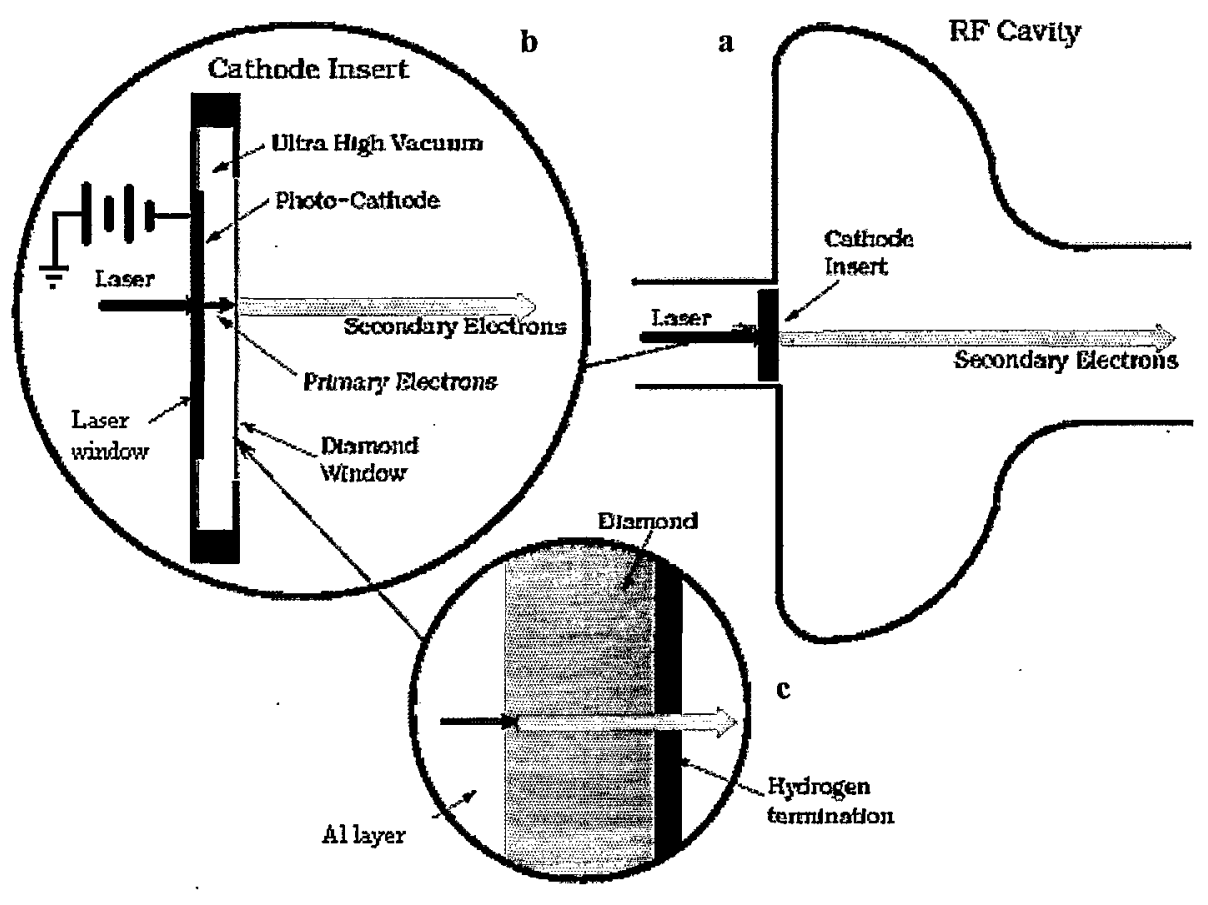


Figure 1. Schematic of the SEEP. See text for details

Figure la shows a cathode insert inside a RF injector. The cathode insert consists of a high $\mathrm{QE}$ primary photocathode, a diamond window, with an insulating spacer between the two, as shown in Figure 1 b. As shown in Figure 1c, the cathode side of the diamond window is coated with a thin metal layer while the cavity side is hydrogenated to result in a Negative Electron Affinity (NEA) surface. A voltage bias in the range of 5 to $10 \mathrm{kV}$ is applied between the primary photocathode and the metal layer on diamond. The laser light passes through the substrate of the primary photocathode and irradiates it, releasing electrons. These electrons are accelerated by the applied field between the primary cathode and diamond, pass through the metal layer into the diamond, to create a shower of secondary electrons. These secondary electrons drift through the diamond in the presence of the RF field in the cavity to emerge from the NEA surface in to the RF cavity to be accelerated further. This scheme has a number of advantages, as listed below:

- Significant reduction in the number of primary electrons required to ' meet the current /charge requirement, resulting in a corresponding reduction in the laser power/energy requirement

- Increase in the life time of the primary photocathode due to reduction in current/charge delivered

- Isolation of the cathode from the cavity vacuum, increasing the life time of the primary cathode

- Isolation of the cavity from the cathode, preserving the performance of the cavity

- Low energy spread of the secondary electrons due to thermalization in diamond and emission from NEA surface

- Simplified transport of the capsule that can be exposed to air

\section{Design criteria:}

The design of the capsule is determined by the operating parameters of the injector and the properties of the diamond. Table 1 lists the properties of diamond relevant to this application.

Table 1 Diamond properties relevant to this application

\begin{tabular}{|l|l|}
\hline Crystal structure & $\begin{array}{l}\text { Diamond Best orientation for NEA is } \\
(111)\end{array}$ \\
\hline Number of atoms in $1 \mathrm{~cm}^{3}$ & $1.764 * 10^{23}$ \\
\hline Debye temperature & $1860 \mathrm{~K}$ \\
\hline
\end{tabular}




\begin{tabular}{|l|l|}
\hline Density & $3.515 \mathrm{~g} / \mathrm{cm}^{3}$ \\
\hline Dielectric constant $\left(10^{2}-10^{4} \mathrm{~Hz}\right)$ & 5.7 \\
\hline Lattice constant & $3.567 \mathrm{~A}$ \\
\hline Breakdown field & $10^{8}-10^{9} \mathrm{~V} / \mathrm{m}$ \\
\hline Mobility electrons & $\leq 2200 \mathrm{~cm}^{2} \mathrm{~V}^{-1} \mathrm{~s}^{-1}$ \\
\hline Mobility holes & $\leq 1800 \mathrm{~cm}^{2} \mathrm{~V}^{-1} \mathrm{~s}^{-1}$ \\
\hline Electron thermal velocity & $\sim 10^{5} \mathrm{~m} / \mathrm{s}$ \\
\hline Melting point (@ $\mathrm{p}=125 \mathrm{kbar})$ & $4373^{\circ} \mathrm{C}$ \\
\hline Specific heat & $0.52 \mathrm{~J} \mathrm{~g}^{-1}{ }^{\circ} \mathrm{C}^{-1}$ \\
\hline Thermal conductivity & $6-20 \mathrm{~W} \mathrm{~cm}-1{ }^{\circ} \mathrm{C}^{-1}$ \\
\hline Thermal expansion, linear & $0.8 \cdot 10^{-6}{ }^{\circ} \mathrm{C}^{-1}$ \\
\hline Saturated electron drift velocity & $2.7 \cdot 10^{7} \mathrm{~cm} / \mathrm{s}$ \\
\hline
\end{tabular}

Diamond has ideal properties for this application. SEY higher than 100 has been measured [9] in the reflection mode. The ability to form NEA surface helps both in the high SEY and the narrow energy distribution of the secondary electrons [10]. The high breakdown field, mobility and saturation velocity of diamond are very important in high field RF environment. The high thermal conductivity helps to dissipate the heat generated by the RF, primary and secondary electron current. With the strength of diamond, it is possible to form free standing structures capable of withstanding a one atmosphere pressure differential across a diamond as thin as 10 micron. For our application, in order to minimize $\mathrm{RF}$ heating and reduce charge trapping, we have chosen undoped preferably large grain size $(>10$ micron or single crystal diamond with impurity concentration $<<$ 1 ppm. (111) surface of diamond results in the best NEA surface and high electron emission, however, as we will show later, other orientations work as well. In the following section, calculations used to determine the dimensions of diamond to deliver $0.200-1$ A current and dissipate the heat generated in the process will be discussed.

\section{Dimensions of the diamond window:}

The thickness is determined by the transport of the electrons through the diamond and phase requirement in RF cavity, the strength of the window for holding pressure during installation as well as the ability to dissipate the heat generated in the process. The calculations below are directed towards two applications: electron cooling of ion beams at RHIC (RHIC II) and the ERL project at BNL. 
For the ERL, the electron beam parameters are, maximum charge of $1.4 \mathrm{nC}$ at repetition rate of $352 \mathrm{MHz}$, into a $703 \mathrm{MHz}$ cavity (high current case). For magnetized electron cooling of RHIC [2], the electron beam parameters are, maximum charge of $20 \mathrm{nC}$ (high charge case) at a repetition rate of $9.4 \mathrm{MHz}$ emitted in to the $703 \mathrm{MHz}$ cavity at $35 \mathrm{deg}$. Since the secondary electrons generated at the cathode side need to drift through the diamond in the presence of the RF field and be emitted in to the cavity at the appropriate phase, they should be generated at $\sim 5$ degrees, with drift time of $\sim 30$ degrees, corresponding to $120 \mathrm{ps}$ for $703 \mathrm{MHz}$. The electron drift velocity in diamond under high external electric field has been experimentally measured [11]. The data shows that when the external field is larger than $2 \mathrm{MV} / \mathrm{m}$ the electron drift velocity is saturated at about $\mathrm{v}_{\mathrm{D}}=2.7 \times 10^{7} \mathrm{~cm} / \mathrm{s}$ and is independent of temperature. This means that the secondary electron bunch drift velocity in diamond is almost constant except when the charge density is very high and the space charge force is comparable to RF field. The optimum diamond thickness for our example is estimated to be:

$t_{D m d}<120 p s \times v_{D}=32 \mu m$

The diameter of the diamond is determined by the required current density, emittance and capability to dissipate the heat generated. Optimization of the current density and emittance dictates the transverse dimension of the electron beam to be $\sim 5 \mathrm{~mm}$ for $1.4 \mathrm{nC}$ and $\sim 7 \mathrm{~mm}$ for the $5 \mathrm{nC}$ charge. The heating of the diamond is caused by a number of sources: the power dissipated by the primary electrons, power dissipated by the secondary electrons passing through the diamond in the RF field, resistive heating by the electron replenishment current flowing through the metal film, power dissipation by the RF currents through the aluminum film and motion of charge carriers induced by impurities. Table I and II list the contribution from each of the effects.

Table I. Thermal contribution for high charge case

$\begin{array}{llll}\text { R } & 10 \mathrm{~mm} & 12.5 \mathrm{~mm} & 15 \mathrm{~mm} \\ \text { Primary } & 6.3(\mathrm{~W}) & 6.3(\mathrm{~W}) & 6.3(\mathrm{~W}) \\ \text { Secondary, } & 7.6(\mathrm{~W}) & 7.6(\mathrm{~W}) & 7.6(\mathrm{~W}) \\ \text { RF } & 7.5(\mathrm{~W}) & 20.0(\mathrm{~W}) & 48.6(\mathrm{~W})\end{array}$




$\begin{array}{llll}\text { Replenishment } & 0.042(\mathrm{~W}) & 0.046(\mathrm{~W}) & 0.054(\mathrm{~W}) \\ \text { Total } & 21.4(\mathrm{~W}) & 33.9(\mathrm{~W}) & 62.5(\mathrm{~W})\end{array}$

Table II. Thermal contribution for high current case

$\begin{array}{llll}\text { R } & 2.5 \mathrm{~mm} & 5 \mathrm{~mm} & 7.5 \mathrm{~mm} \\ \text { Primary } & 33.3(\mathrm{~W}) & 33.3(\mathrm{~W}) & 33.3(\mathrm{~W}) \\ \text { Secondary } & 40.2(\mathrm{~W}) & 40.2(\mathrm{~W}) & 40.2(\mathrm{~W}) \\ \text { RF } & 0.046(\mathrm{~W}) & 0.67(\mathrm{~W}) & 3.4(\mathrm{~W}) \\ \text { Replenishment } & 0.025(\mathrm{~W}) & 0.023(\mathrm{~W}) & 0.023(\mathrm{~W}) \\ \text { Total } & 73.6(\mathrm{~W}) & 74.2(\mathrm{~W}) & 76.9(\mathrm{~W})\end{array}$

A code was written to simulate the temperature distribution across the diamond due to these four contributions, taking into account, the correct temperature dependent material properties, such as thermal conductivity and resistivity. The intermittent nature of the current is accounted for by considering peak and average current effects. In each of the simulations, the edge of the diamond was assumed to be clamped at a given temperature and the transverse temperature distribution from the center $(R=0)$ to the edge was simulated. The results of the simulation for different radii and thickness of diamond, thickness of metallic film and edge temperature are shown in figures 2-7. The electron beam parameters for the high charge case are: charge $20 \mathrm{nC}, \mathrm{PRF} 9.4 \mathrm{MHz}, \mathrm{RF}$ peak field $15 \mathrm{MV} / \mathrm{m}$, electron bunch length $40 \mathrm{ps}$, primary electron energy $10 \mathrm{keV}$, and SEY 300 . For the high current case, the charge is $1.42 \mathrm{nC}$ and PRF $703 \mathrm{MHz}$ while other parameters remain the same. For subsequent measurements and capsule design, the physical dimensions of diamond were chosen to be $30 \mu \mathrm{m}$ thickness and 10 $\mathrm{mm}$ diameter with $\sim 7 \mathrm{~mm}$ diameter active area for electron emission. 


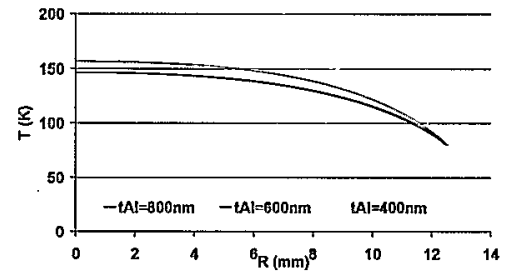

Figure 2 Temperature distribution for different Al thickness. $\mathrm{R}=12.5 \mathrm{~mm}$, High Charge regime

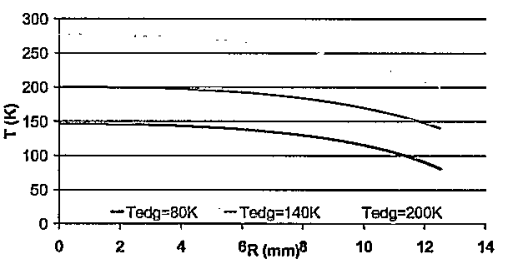

Figure 4 Temperature distribution for different edge temperatures. Al thickness $800 \mathrm{~nm}$,

$\mathrm{R}=12.5 \mathrm{~mm}$, high charge regime

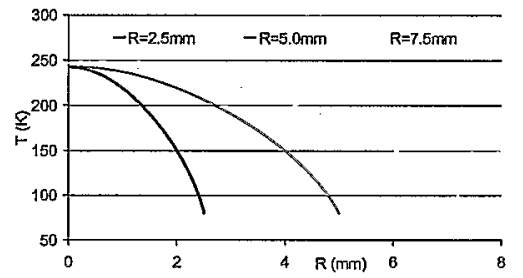

Figure 6. Temperature distribution for different radii. Al thickness $800 \mathrm{~nm}$, high current regime

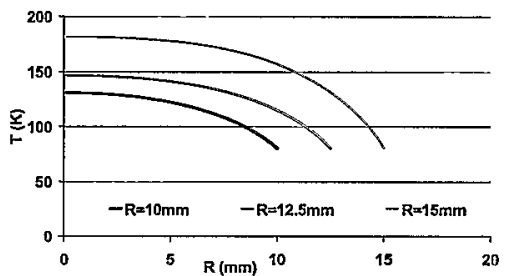

Figure 3. Temperature distribution for different radii of diamond. Al thickness is $800 \mathrm{~nm}$, high charge regime

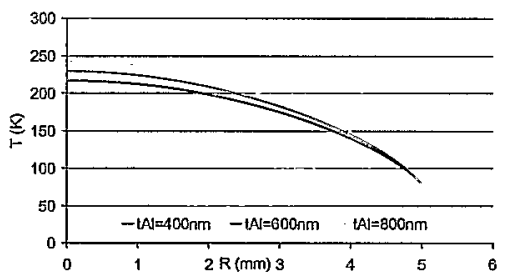

Figure 5 Temperature distribution for different Al thickness. $R=5 \mathrm{~mm}$, High current regime

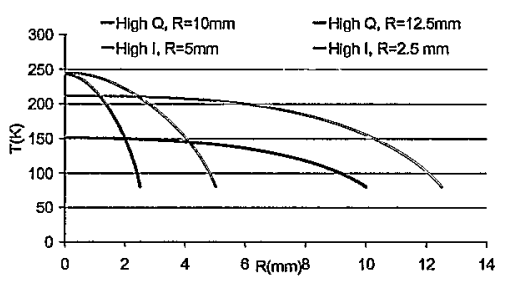

Figure 7. Temperature distribution for $30 \mathrm{~nm}$ Au for different radii, high charge( $Q$ ) and high current(I) regime 


\section{Metal layer:}

Since the diamond is chosen to be undoped, a conducting layer on the cathode side of the diamond is needed to provide the replenishment current. Careful analysis and experiments of thin metal films on dielectric material at the cathode center of the RF cavity [12] indicate that even with a metal layer as thin as $10 \mathrm{~nm}$, the RF penetration through the film is small and the metal acts rather as the return path for the RF current. Furthermore, since the primary electrons need to pass through this layer before impacting the diamond, energy loss of the primary electrons in this layer not only adds to the heating effect, but also reduces the SEY. The material and its thickness should be chosen to minimize the energy reduction of the primary electrons as well as the resistance. Other considerations are the ability to make good electrical and thermal the contact with diamond, ruggedness and compatibility with fabrication process and the primary electron source. Presently aluminum, gold and $\mathrm{Ti} / \mathrm{Pt} / \mathrm{Au}$ are being considered with the thickness ranging from $800 \square$ to $300 \square$.

\section{Hydrgenation:}

For efficient electron emission, the cavity side of the diamond needs to be an NEA surface. It has been shown that cesiated or hydrogenated diamond [13] result in NEA surface with $<1 \mathrm{eV}$ and $\sim 0.3 \mathrm{eV}$ negative affinity respectively. Since the presence of cesium is not desirable in a SRF cavity, for our application, the diamond will be hydrogenated to provide the NEA surface.

\section{Primary Cathode:}

Although the concept is valid for any primary electron source, our application requires short electron bunches with tens of $\mathrm{pC}$ and up to a few $\mathrm{mA}$ average current. Semiconductor photo cathodes such as $\mathrm{CsK}_{2} \mathrm{Sb}$ [7, 14] and GaAs:Cs [8] have shown to meet these requirements. In subsequent design considerations, $\mathrm{CsK}_{2} \mathrm{Sb}$ will be considered as cathode of choice, mostly because of its prompt emission.

\section{Secondary Electron Beam Quality:}

Unlike in a conventional RF injector, in SEEP, the beam quality is modified by passage of the electrons through the diamond. The energy distribution and bunch length are modified by collisions with other electrons and phonons. Monte Carlo simulations [15] of electron transport in the presence of high electric field in the diamond indicate that for the fields of $\sim 10 \mathrm{MV} / \mathrm{m}$, fields anticipated in our application, the average energy of the electrons is in the range of $100 \mathrm{meV}$ and the drift velocity saturates to $\sim 10^{5} \mathrm{~m} / \mathrm{s}$. Hence if the space charge field does not 
reduce the RF field significantly, a condition easily met in our application, the electron bunch length would not change during the passage through the diamond. However, since the secondary emission process is statistical, a fraction of the primary electron may straggle [16] over a distance of 0.4 micron, giving rise to a bunch lengthening of $\sim 2.6$ ps. This value can be reduced by lowering the primary electron energy, at a price of reduced amplification. Hence the electron beam emitted from the diamond is expected to have a very low emittance.

\section{Experiments:}

The primary goals of the experiments were to investigate a number of diamond samples to determine the critical parameters of the diamond, establish sample preparation and hydrogenation processes, measure the SEY in transmission and emission mode, and investigate the critical steps towards the fabrication of the capsule.

\section{Sample preparation:}

Chemical treatment:

All the samples were chemically treated prior to measurement to remove metallic and organic impurities from the surface. The process is as follows:

15 minutes in fuming solution of saturated $\mathrm{CrO}_{3}$ in $\mathrm{H}_{2} \mathrm{SO}_{4}$

2 minutes in $\mathrm{NH}_{3} \mathrm{OH}$ in ultrasonic bath

2 minutes in $\mathrm{HCl}: \mathrm{H}_{2} \mathrm{O}(1: 10)$ in ultrasonic bath

5 minutes in boiling $\mathrm{H}_{2} \mathrm{SO}_{4}: \mathrm{H}_{2} \mathrm{O}_{2}(5: 1)$

2 minutes in boiling $\mathrm{NH}_{3} \mathrm{OH}: \mathrm{H}_{2} \mathrm{O}_{2}(1: 1)$

2 minutes in boiling $\mathrm{HCl}: \mathrm{H}_{2} \mathrm{O}_{2}: \mathrm{H}_{2} \mathrm{O}(1: 1: 4)$

5 minutes in DI water in ultrasonic bath

Each step is followed by DI water rinse, and the final step is drying by nitrogen gas jet.

Immediately after chemical treatment, $300 \square-500 \square \mathrm{Al}$ was evaporated on either side of the sample for transmission measurements. For emission measurements, the samples were coated with $300 \square$ of gold on one side and hydrogenated on the opposite side. Care was taken to minimize the time the sample was exposed to air.

Hydrogenation:

The photograph of the chamber used for hydrogenation is shown in Figure 8. The chamber consists of a stainless steel sample holder, a tungsten filament, and a leak valve to introduce molecular hydrogen into the chamber. The sample holder and tungsten filament can be heated electrically to $900 \mathrm{C}$ and $1800 \mathrm{C}$ respectively. The temperature was measured using a calibrated pyro viewer and the pressure with the cold cathode gauge. The chamber is also equipped with a 
fused silica window for viewing and illuminating the sample. An anode suitably biased can also be positioned in front of the sample to enable photoemission measurements from the sample.

After metallization, the sample was inserted in the hydrogenation chamber and pumped till the base pressure is in the range of 1-3 nTorr. The sample holder and the sample are then heated to $800 \mathrm{C}$ for 30 minutes in order to clean the sample as well as break the $\mathrm{C}-\mathrm{O}$ bonds on the surface in readiness for hydrogenation. Once the sample is cooled and the vacuum is returned to nTorr level, $2 \mu$ Torr of $\mathrm{H}_{2}$ is introduced in to the chamber and the tungsten filament is heated to $1800 \mathrm{C}$ for 15 minutes. The interaction between the hot filament and the molecular hydrogen gas releases atomic hydrogen that attaches to the free dangling carbon bonds on the surface of the diamond, thereby hydrogenating it and generating a NEA surface. The sample is then removed from the hydrogenation chamber and installed in the Secondary Electron Yield (SEY) test chamber.

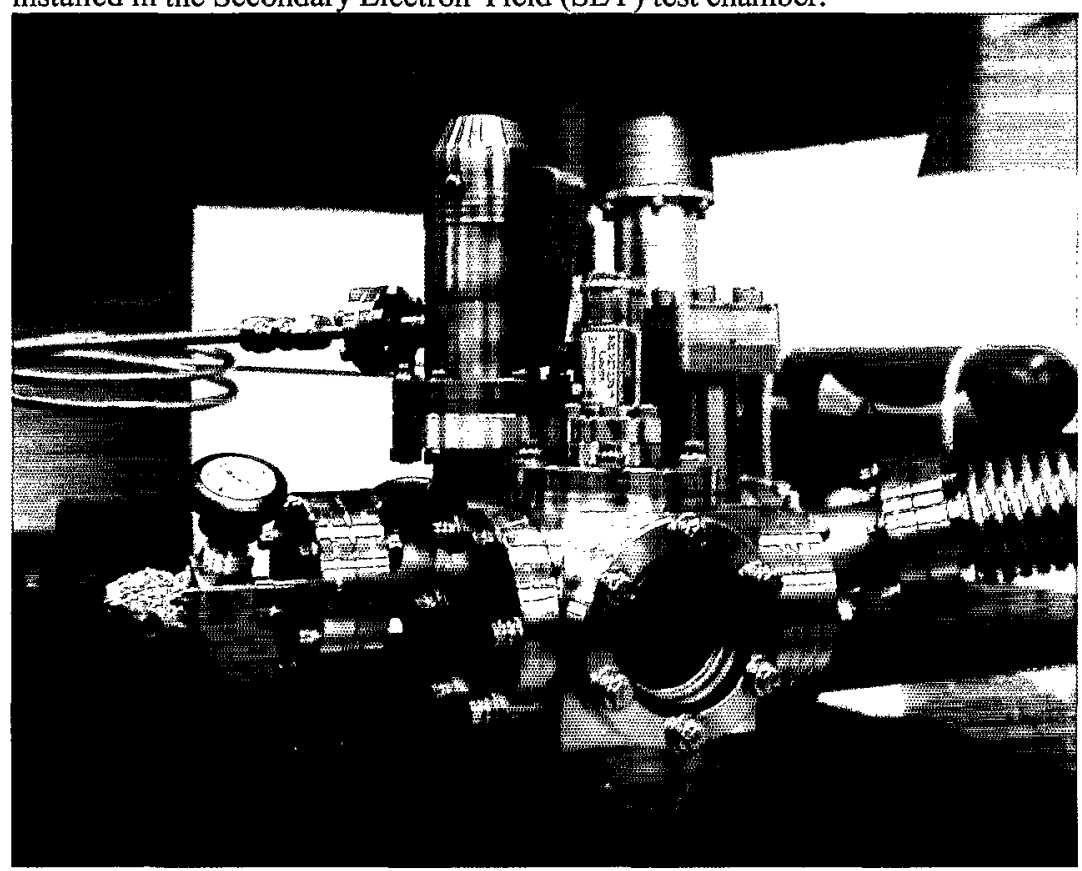

Figure 8. Photograph of the hydrogenation cell

\section{Experimental arrangement:}

Two sets of measurements, SEY in transmission mode and SEY in emission mode, were made on the samples. For the transmission measurements, the sample with metallic coating on both the polished faces was sandwiched between two stainless steel holders (electrodes) that are electrically isolated from each 
other by a kapton layer. Each of these holders makes contact with the metallic coating on its side of the diamond and can be biased up to $5 \mathrm{kV}$. The holder on the primary side has a small hole to let the primary electron through. The signal of the primary current arriving on one side of the diamond and the secondary current leaving the opposite side of the diamond are fed to an oscilloscope. Current due to either electron or hole as the charge carrier can be measured by using bias of appropriate polarity on the electrodes. The schematic of the arrangement is shown in Figure 9. For emission measurements, only the primary side of the diamond is metalized. The opposite face is hydrogenated. The secondary electrode is not in contact with the diamond, but is positioned away from it. The width of the vacuum gap is determined by the thickness of the diamond and the voltage applied such that the field across the diamond is sufficient to transport the electrons through it.

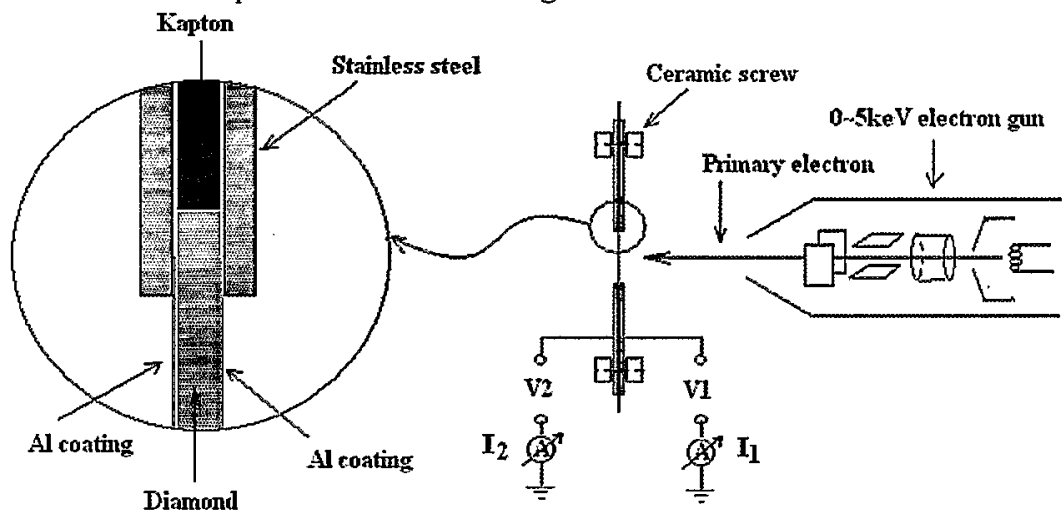

Figure 9. Schematic of the experimental arrangement. For the transmission measurements, both the surfaces of the diamond are coated with Al. The metal electrodes contact the Al coating on both sides. For emission measurements, the surface facing the electron gun is coated with Au and the opposite surface is hydrogenated. The electrode on primary side is in contact with Au and the electrode on secondary side is isolated from diamond by the vacuum gap.

The sample in the holder is mounted on a linear manipulator and installed in a vacuum chamber equipped with an electron gun and energy analyzing system. For the measurements described below, the energy analyzing system was not used. The electron beam from the gun is used as the primary electron and has the following parameter ranges: electron energy-1-5 keV, current $10 \mathrm{nA}-10 \mu \mathrm{A}$, radius of the focused beam is estimated to be $\sim 150 \mu \mathrm{m}$. The energy of the electrons entering the diamond is reduced by the loss in the metallic layer and increased by the bias on the primary electrode.

\section{Experimental Results:}


A number of samples from different vendors and different crystalline properties were tested. Since the crystal dimensions were different, for each of the samples, even though the general lay out of the sample holder remained the same, the size of the hole in the holder on the primary side was varied to accommodate the varied sample sizes. Table III lists the sample parameters, experimental arrangement and results.

Table III. Specifications and the performance of different diamond samples tested

\begin{tabular}{|c|c|c|c|}
\hline Vendor & Sample parameters & $\begin{array}{c}\text { Ranges of } \\
\text { Experimental } \\
\text { parameters }\end{array}$ & Results \\
\hline $\begin{array}{l}\text { Element-Six } \\
\text { Diafilm OP }\end{array}$ & $\begin{array}{l}\text { CVD } \\
\text { crystalline, } 6 \mathrm{~mm} \\
\text { diameter } 0.2 \mathrm{~mm} \\
\text { thick, central } 4 \mathrm{~mm} \\
\text { coated with } \mathrm{Al}, 20 \\
\text { nm on primary side } \\
\text { and } 50 \mathrm{~nm} \text { on } \\
\text { secondary side. } 2.5 \\
\text { mm hole in the } \\
\text { primary electrode }\end{array}$ & $\begin{array}{l}\text { Primary } \\
\text { current: } 10 \mathrm{nA}- \\
5 \mu \mathrm{A} \text {, } \\
\text { Energy } 1-6 \\
\mathrm{keV} . \\
\text { Bias across } \\
\text { diamond to } 5 \\
\mathrm{kV}\end{array}$ & $\begin{array}{l}\text { No electron or hole } \\
\text { current }\end{array}$ \\
\hline $\begin{array}{l}\text { Apollo } \\
\text { Diamonds }\end{array}$ & $\begin{array}{l}\text { CVD single crystal, } \\
\text { Type II a, } 6 \mathrm{~mm} \\
\text { diameter, } 0.2 \mathrm{~mm} \\
\text { thick central } 4 \mathrm{~mm} \\
\text { coated with } \mathrm{Al}, 30 \\
\text { nm on primary side } \\
\text { and } 50 \mathrm{~nm} \text { on } \\
\text { secondary side. } 2.5 \\
\text { mm hole in the } \\
\text { primary electrode, }\end{array}$ & $\begin{array}{l}\text { Primary } \\
\text { current: } 100 \\
\mathrm{nA} \text { to } 8.5 \mu \mathrm{A} \\
\text { Electron } \\
\text { energy } 1-8 \mathrm{keV} \\
\text { Field across } \\
\text { diamond : } 10- \\
20 \mathrm{MV} / \mathrm{m}\end{array}$ & $\begin{array}{l}\text { SEY Transmission } \\
\text { mode up to } 200 \\
\text { SEY decreases } \\
\text { with increasing } \\
\text { primary current } \\
\text { indicating } \\
\text { saturation } \\
\text { secondary current. } \\
\text { Neither the rise } \\
\text { and fall times were } \\
\text { prompt. Response } \\
\text { time was in the } \\
\text { order of minutes. } \\
\text { Gain vanished } \\
\text { when sample was } \\
\text { cooled to } 80 \mathrm{~K}\end{array}$ \\
\hline $\begin{array}{c}\text { Element-Six } \\
\text { detector grade }\end{array}$ & $\begin{array}{l}\text { CVD, single crystal, } \\
\text { low impurity } \\
\text { concentration, } 4 \mathrm{~mm} \\
\text { square with } 0.25 \\
\text { mm thick }\end{array}$ & $\begin{array}{l}\text { Primary current } \\
50 \mathrm{nA} \\
\text { Energy: } 4 \mathrm{keV} \\
\text { Field across } \\
\text { diamond up to }\end{array}$ & $\begin{array}{l}\text { SEY transmission } \\
\text { mode electron } \\
\text { current very high, } \\
\text { strong dependence } \\
\text { on the field. SEY }\end{array}$ \\
\hline
\end{tabular}




\begin{tabular}{|c|c|c|c|}
\hline & & $6 \mathrm{MV} / \mathrm{m}$ & $\begin{array}{l}\text { transmission mode } \\
\text { hole current } \sim 30 \text {, } \\
\text { nearly linear } \\
\text { dependence to } \\
\text { field }\end{array}$ \\
\hline UralAlmazInvest & $\begin{array}{l}\text { Natural Type II a } \\
\text { single crystal }(110) \\
3 \times 2.64 \times 0.16 \mathrm{~mm}^{3} \text {, } \\
60 \mathrm{ppm} \text { nitrogen, } \\
\text { central } 2 \mathrm{~mm} \text { coated } \\
\text { with } 30 \mathrm{~nm} \text { thick } \\
\mathrm{Al}, 1.5 \mathrm{~mm} \text { hole in } \\
\text { the primary } \\
\text { electrode for } \\
\text { transmission } \\
\text { measurements }\end{array}$ & \multicolumn{2}{|c|}{ Data shown below } \\
\hline $\begin{array}{l}\text { Element-Six } \\
\text { Diafilm El } \\
\text { (electronic } \\
\text { grade) }\end{array}$ & $\begin{array}{l}\text { CVD } \\
\text { Polycrystalline, low } \\
\text { impurity } \\
\text { concentration, } 10 \\
\text { mm diameter, } 0.45 \\
\text { mm thick, one side } \\
\text { coated with } 30 \mathrm{~nm} \\
\begin{array}{l}\mathrm{Au} \text { other side } \\
\text { hydrogenated }\end{array}\end{array}$ & \multicolumn{2}{|c|}{ Data shown below } \\
\hline
\end{tabular}

Measurements with natural diamond:

The natural diamond sample (UralAlmazInvest) is single crystal (110) with physical dimensions of $3 \times 2.64 \times 0.16 \mathrm{~mm}^{3}$ both sides polished to an optical quality finish. The vendor specifications indicate the nitrogen concentration to be $60 \mathrm{ppm}$ and other impurity levels to be below measurable level. Optical and scanning electron microscope studies of the sample indicate very good surface quality. X ray spectroscopy confirms this sample to be single crystal (110).

For transmission measurements, the central $2 \mathrm{~mm}$ of chemically treated sample was coated with $30 \mathrm{~nm} \mathrm{Al}$. The secondary electron yield was measured as a function of primary electron energy, current and the field in the diamond at 300 $\mathrm{K}$ and at $80 \mathrm{~K}$. The results are shown in Figures 10 and 11. Maximum gain of 220 has been measured with primary electrons of $5 \mathrm{keV}$ energy. The difference in the maximum gain between the $300 \mathrm{~K}$ and $80 \mathrm{~K}$ measurements is due not to the temperature, but to the spatial variation typically found in the natural diamond. The gain has a very small dependence on the primary current, the cause of it still under investigation. The observed threshold on the primary 
electron energy is due to the energy loss in the Al layer. At both the temperatures, the gain shows a very steep increase at low fields and a lower rate of increase at higher fields. If we define the gain value at this knee point as the maximum SEY for this primary electron energy, the SEY is linearly dependent on the primary electron energy as expected, with an intercept of $\sim 2 \mathrm{keV}$ and a slope of 14. The intercept is a measure of the energy lost in the Al layer and agrees well with the calculated energy loss in $30 \mathrm{~nm}$ of Al. The slope is the energy required to form an electron hole pair in diamond and is consistent with other reports [17].

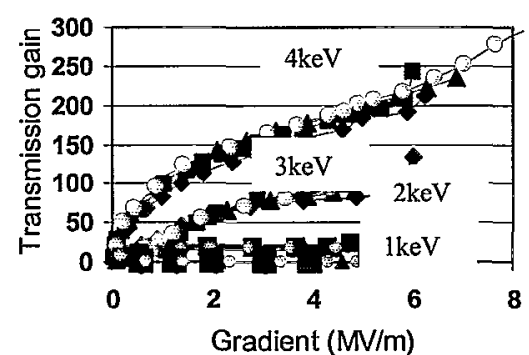

Figure 10. Gain measurements for different primary currents and energies in transmission mode at $300 \mathrm{~K}$

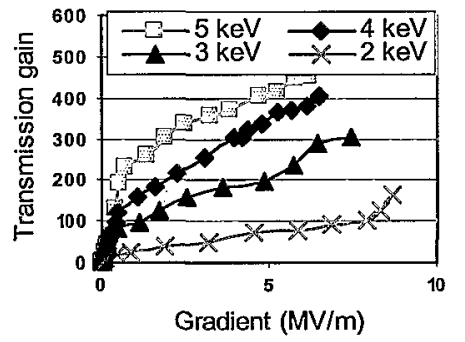

Figure 11. Gain measurements at different energies in transmission mode at $80 \mathrm{~K}$

For emission measurements, the center of one of the surfaces was coated with 5 $\mathrm{nm}$ of $\mathrm{Cr}$ followed by $15 \mathrm{~nm}$ of $\mathrm{Au}$ and the opposite face was hydrogenated. The metalized surface was in contact with the primary electrode. The secondary electrode was electrically isolated from the sample through a $0.025 \mathrm{~mm}$ vacuum gap. Care was taken to shield the metal with kapton to prevent arcing. The gain was measured as a function of primary electron energy, current and the field on diamond. The gain curve for $50 \mathrm{nA}$ current for different electron energies is shown in Figure 12. A maximum gain of 38 was measured, with an electron energy of $5 \mathrm{keV}$ and a field of $1.7 \mathrm{MV} / \mathrm{m}$. The gain is limited by the maximum field that can be applied to the sample. Although this demonstrated gain is lower than that measured in the transmission mode, it is already sufficient to lower the required laser power significantly. All the gain curves have a threshold field of $1 \mathrm{MV} / \mathrm{m}$, the origin of which is still under investigation. 


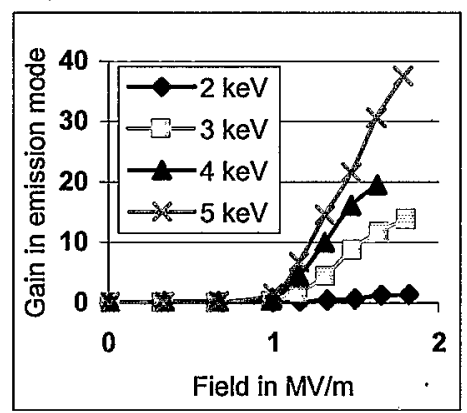

Figure 12. Gain measurement from natural diamond, in emission mode for different primary energies, with $50 \mathrm{nA}$ primary current at $300 \mathrm{~K}$

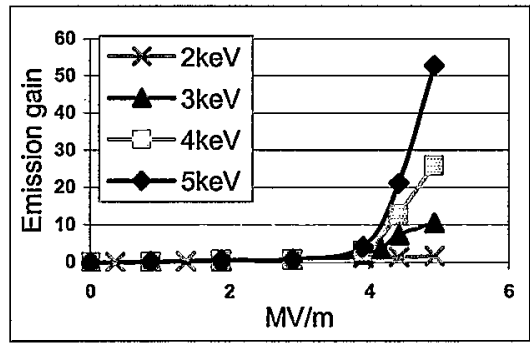

Figure 13. gain measurements on CVD polycrystalline sample for primary current of $100 \mathrm{nA}$ at 300 K different primary energies

Measurements with CVD polycrystalline diamond:

The diamond sample used for these measurements was a polycrystalline (Diafilm EL from Element-Six) sample, $10 \mathrm{~mm}$ diameter and $0.45 \mathrm{~mm}$ thick, both sides polished to an optical quality finish. The vendor specification indicates that all the impurity levels are below measurable limit. $X$ ray crystallography of similarly grown, unpolished sample shows presence of (110) and (111) orientation, although the ratio is expected to change during polishing, owing to the higher hardness of the (111). After chemical treatment, one of the polished surfaces was coated with $30 \mathrm{~nm}$ of $\mathrm{Au}$ and the other surface was hydrogenated. Experimental arrangement was similar to that of the natural diamond, except for a larger vacuum gap of $0.088 \mathrm{~mm}$. Gain in the emission mode as a function of primary current and energy are shown in Figures 13. Gain as large as 50 has been measured with primary electron energy of $5 \mathrm{keV}$. As in the natural diamond, the gain curves have a threshold field, but of a larger magnitude $(\sim 4$ $\mathrm{MV} / \mathrm{m}$ ) in this sample.

\section{Capsule Fabrication:}

In SEEP, a highly sensitive primary cathode and a specially prepared diamond need to be integrated to form a capsule that can be seamlessly installed in the (SRF in our application) injector. The first step towards the design and 
fabrication of such a capsule is investigating the techniques to bond diamond to $\mathrm{Nb}$ which can then be installed in the SRF cavity. Brazing was chosen to be bonding process and the first diamond was brazed to $\mathrm{Nb}$ successfully by a commercial vendor (Delaware Diamond Knives). Subsequently, a number of diamond samples were brazed to $\mathrm{Nb}$ in house, in a vacuum oven and reproducible brazing technique has been established. Presently we are in the process of polishing and thinning the brazed diamond to the required dimension and finish. In parallel, a capsule with metal photocathode is being designed and built to test the entire fabrication process.

\section{Conclusion:}

Theoretical calculations indicate that SEEP using diamond as a secondary emitter is a very promising technique to achieve very high average current, high quality electron beams. Electron beams with charges up to $5 \mathrm{nC}$ and current up to 0.5 A can be delivered from $\sim 30$ micron thick diamond coated with $800 \mathrm{~nm}$ $\mathrm{Al}$ from a radius up to one $\mathrm{cm}$. Heat generated during the process can be easily dissipated by cooling the edges to liquid nitrogen temperatures. Our experimental results show SEY as high as 37 and 52 in the emission mode from natural single (110) crystal and high purity CVD poly crystal respectively. The SEY measurements on different samples indicate that the magnitude of the SEY depends strongly on both the quality of the crystal and on the impurity level. The mechanisms leading to high threshold fields for the gain and the role of impurities, crystal grain boundaries and the cause for lower SEY in emission mode in comparison to the transmission mode are under investigation. Future plans include investigating the temporal response of SEY, and demonstration of higher currents, measuring secondary electron energy distribution, and establishing good metal/diamond interface and testing in RF cavity. Diamond has been brazed successfully to $\mathrm{Nb}$ numerous times and efforts are underway to fabricate the capsule and test the emission from the capsule.

\section{Acknowledgments}

The authors would like to thank J. Walsh and D. Pate for their expert technical assistance. This manuscript has been authored by Brookhaven Science Associates, LLC under Contract No. DE-AC02-98CH10886 with the U.S. Department of Energy. The United States Government retains, and the publisher, by accepting the article for publication, acknowledges, a world-wide license to publish or reproduce the published form of this manuscript, or allow others to do so, for the United States Government purposes. 


\section{References}

1. Litvinenko V. N. , Beavis D., et al. "High Current Energy Recovery Linac at BNL", Proc. of PAC 05, Knoxville TN, p 2242

2. Ben-Zvi I. , Brennan J., et al. "R\&D towards cooling of the RHIC Collider" NIM A 532 (2004) 177-183

3. Workshop on Photo-injector for Energy Recovery Linac, January 22 \& 23, 2001 Brookhaven National Laboratory Upton, NY, http://www.nsls.bnl.gov/organization/Accelerator/highlights/workshop/PERL\%20Injecto r\%20Workshop\%20Proceeding.pdf

4. Srinivasan-Rao T. , Schill J., Ben-Zvi I. , and Woodle M. , "Sputtered Magnesium as a photocathode Material for RF Injectors" Review of Scientific Instruments, 69, (1998), pp 2292-2296

5. http://www-ssrl.slac.stanford.edu/lcls/parameters.htm

6. Suberlucq G., Proc. Of EPAC 2004, Lucerne, Switzerland, (2004) p 64

7. Dowell D., Bethel S.Z., Friddell K. D., " Results from the average power laser experiment photocathode injector test" NIM A 356, (1995), 167

8. Rao T. et al. "Photocathodes for the energy recovery Linacs" NIM A 557 (2006), Pp 124130

9. Yater J. E. and Shih A. "Secondary electron emission characteristics of single-crystal and polycrystalline diamond", J. Appl. Phys., Vol. 87, No. 11, 8103, I June 2000

10. Yater J. E. , Shih A., Butler J. E. Pehrsson P. E. " Transmission of low energy electrons in boron doped nanocrystalline diamond films" J. Appl. Phys. Vol. 93, (2003) Pp 30823089

11. Nebel C E and Stutzmann M Properties, Growth and Applications of Diamond (Emis Data Reviews Ser. 26) ed M H Nazare and A J Neves (London: INSPEC)( 2001) p 40

12. Zhao Y. , Ben-Zvi I. , et al. "The Penetrability of a Thin Metallic Film Inside the RF Field", Proc. Of PAC 05, Knoxville TN p 3073

13. Minoru Niigaki, Toru Hirohata, et al., "Extremely High Quantum Photoyield from Cesiated Polycrystalline Diamond Films", Jpn. J. Appl. Phys. Vol. 37 (1998) pp. L1531L1533

14. Burrill A., Ben-Zvi I., et al. "Multi-Alkali Photocathode Development at Brookhaven National Lab for Application in Superconducting Photoinjectors", Proc. Of PAC 05, Knoxville TN, p 2672

15. Watanabi T., Teraji T., Ito T., “ Monte Carlo simulations of electron transport properties of diamond in high electric fields using full band structure", J. Appl. Phys. Vol. 95 (2004) p. 4866

16. Chuan-Jong Tung, "CSDA Ranges of Electrons in Metals", Chiinese Journal Of Physics, Vol. 17, no. 1, Spring 1979

17. Pernegger H. Roe S. et al. "Charge carrier properties in synthetic single crystal diamond measured with the transient-current technique" J. Appl. Phys. 97 (2005) p 073704 